\title{
Anomie as an antecedent of belief in conspiracy theories: social psychological perspectives
}

Olivier Klein, Center for social and cultural psychology, Université Libre de Bruxelles, Belgium. Email: oklein@ulb.ac.be

The term anomie (sometimes translated anomia) has been coined by the French sociologist Emile Durkheim (1897). In sociology, it refers to a condition in which society provides little moral guidance to individuals. It reflects the breakdown of the social bonds between an individual and the community and the ensuing rise of moral disruption. As this definition makes clear, it is also a hybrid notion given that its two components, the breakdown of social ties and the absence of norms (lack of moral guidance) are two distinct constructs. The concept bears in itself a theoretical assumption about the relation between these two constructs (one causes the other).

Anomie is often cited as explaining the popularity of conspiracy theories. Why? As we shall see, several explanatory mechanisms are proposed. They are all based on the assumption that psychological phenomena mediate the relation between anomie and endorsement of conspiracy theories. I will attempt to sketch this argument, which is loosely based on Marx's theory of alienation: As social ties with the community dissolve, people may not endorse widely accepted narratives, and especially those emanating from authorities. This may be because the world becomes more uncertain and they are seeking new explanations or it may be because their estrangement from authorities, or the deterioration of their own social standing, leads them to distrust these authorities. Hence, they may seek explanations for this state of affairs and especially those involving malevolent forces. Such sense making may represent an attempt to reassert power over their environment and fulfill a need for certainty and control. It may also respond to a desire to find "a tangible enemy to externalize their feelings" (Goerzel, 1994, Volkan, 1985). I tried to sketch this multifaceted theoretical account in figure 1.

As you can see when viewing this figure, there is an ambiguity as to which component of anomie should impact on the "mediators". Thus, dissolution of social ties could lead to distrust in authorities, to uncertainty or to lack of control (all for obvious reasons). But, the other component, dissolution of moral norms could also lead to distrust in authorities (viewed as immoral), uncertainty and lack of control (both because of a lack of moral guidance) and even the externalization of one's feelings (e.g., because of the feeling of threat associated with a lack of moral compass). The only aspect that is uniquely predicted by one of the variables is 
exposure: Thus, as social ties are loosened, people are presumably less exposed to the official narrative and more exposed to distinct narratives.

\section{Figure 1}

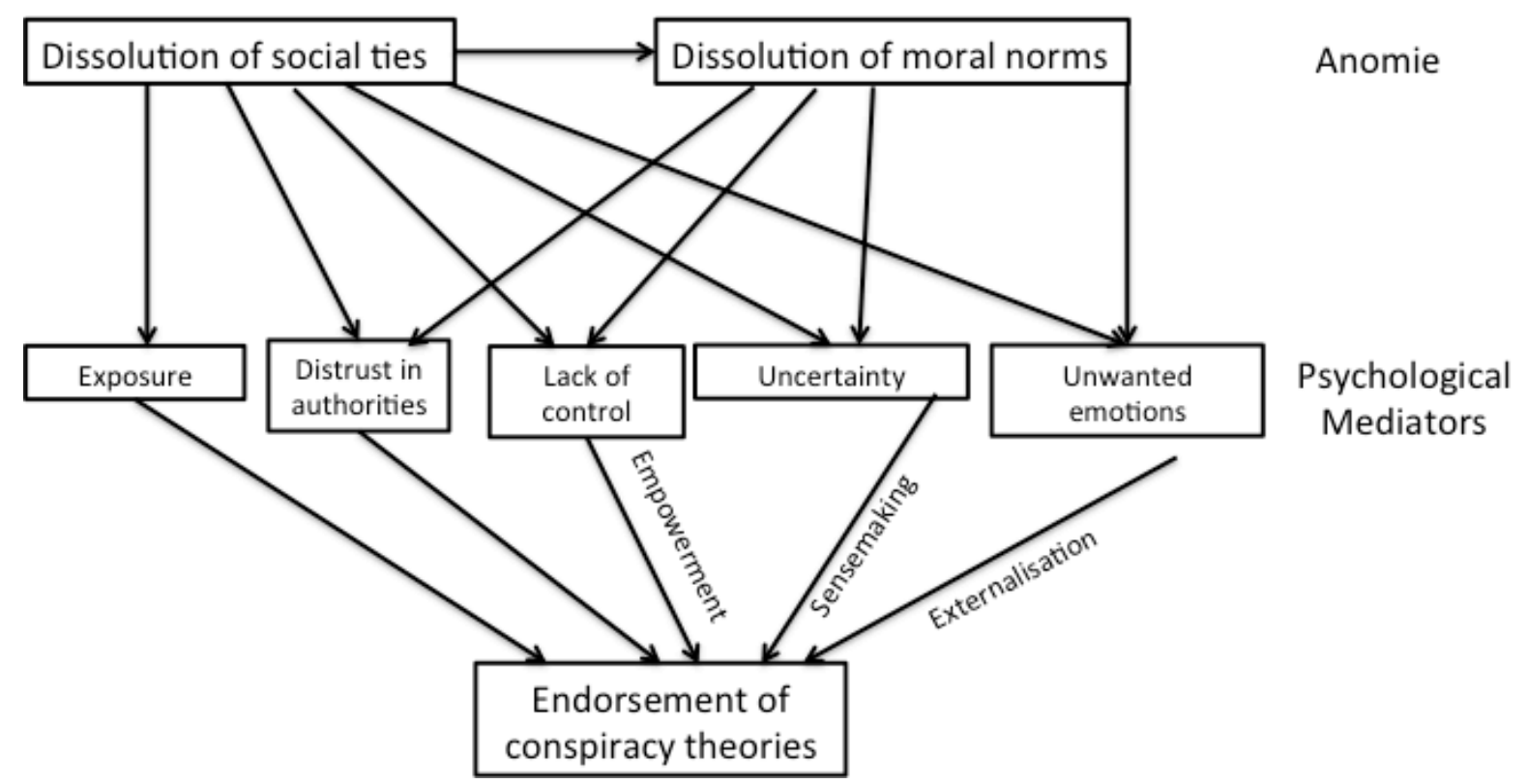

It is very difficult to test the hypothesis that anomie leads to endorsement of CTs because it involves measuring the breakdown of social ties in multiple groups varying on this dimension and correlate it with the average endorsement of conspiracy theories in these societies. I know of no such attempt to do this. However, indirect evidence for the link between anomie and belief in conspiracy theories comes from the observation that, in Western Democracies, members of minority groups are often more likely to espouse conspiracy theories (see e.g., Oliver \& Wood, 2014). If we assume that minorities may be more detached from authorities or the State, this may be consistent with an explanation in terms of anomie.

To eschew the methodological difficulties associated with tackling the sociological level of analysis, social psychologists interested in the relation between anomie and endorsement of CTs have generally resorted to intraindivdiual measures of the concept. To do so, they have either tried to measure the psychological perception of anomie or to measure some of the consequence of anomie depicted in figure 1, such as lack of trust in authorities, lack of control, etc. (i.e., mediators).

In the first attempt to do so, Goerzel (1994) evaluated anomie in a diversified US sample based on three items: "the belief that the situation of the average person is getting worse", "it 
is hardly fair to bring a child into today's world", "most public officials are not interested in the average man". This is a very narrow understanding of the concept. Goerzel found that endorsement of these beliefs was strongly associated with belief in then popular conspiracy theories. More importantly, he found that anomie mediated the relation between minority status (i.e., being African American or Hispanic as opposed to Caucasian) and endorsement of these CTs. Thus, minority groups endorsed these CT more because they experienced more anomie. Belief in CT was also associated with lack of interpersonal trust towards police, neigbours, judicial system (which can be viewed as a component, or a consequence, of anomie).

In another "early" study, Abalakina-Paap et al. (1999) probed belief in 20 conspiracy theories in a sample of US students. They used a measure of anomie developed by Srole (1956) that include the following aspects: the sense that community leaders are detached from the individuals' needs, the individual's perception of the social order as unpredictable, the feeling that one's status is declining, the deflation of internalized social norms, the perception that one's social network is no longer predictive or supportive. Abalakina et al. find that this measure is the best predictor of endorsement of conspiracy theories, contrary e.g., to trust. Note that powerlessness (which can be considered as a consequence of anomie) was an independent predictor of endorsement of these beliefs but not self-esteem, tolerance of ambiguity or attributional complexity.

Wagner-Egger and Bangerter (2007) have measured anomie in a Swiss (French speaking) student sample. In order to do so, they relied on the a measures containing two dimensions: distrust towards institutions and what they call lack of control on the social environment. Howeverr, when looking at their measure of the latter dimension (an item such as "the rich are getting richer and the poor poorer", it seems to capture a sense of deterioration of the social fabric more than lack of control. They also used Goerzel's measure of interpersonal trust. They probed beliefs in eight CTs and found that these could be subdivided in two categories: System-based conspiracy theories (i.e. JFK assassination by the CIA, Appolo didn't land on the moon) and minority associated CTs ("Al Qaida wants to overthrow Western democracies", "AIDS was created by the US government to affect the Black population everywhere" ). Their anomie scale as well as their measure of trust predicted endorsement of both types of CT. They also found that of the multiple potential predictors of beliefs in CT, paranoia, anomie, belief in a dangerous world and distrust (but not life satisfaction and measures related to fear 
of uncertainty) loaded on a single factor. Scores on this factor were the strongest predictor of endorsement of system-based CTs (with irrationality ${ }^{1}$ )

Swami (2012) measured belief in Jewish conspiracy ("Jews have too much power", "Jews are to blame for the detrimental effects of globalization"...) among ethnic Malays in Malaysia: He measured components/correlates of anomie, such as political alienation (i.e., selfperception as not understanding anything about politics), attitude to authority, political cynicism (a scale that included three dimensions: concern for public interest, idealism and political determination) and satisfaction with life. These however did not predict conspiracist beliefs regarding Jews or conspiracist ideation in general generally when other relevant predictors were entered in the model. In a subsequent study, Swami finds that endorsement of the Jewish conspiracy theory in this population does not reflect a general tendency to beleive in CTs but is much more related to immediate socio-political concerns (e.g., such as the role of Israel).

Note that, contrary to these findings, in another study, conducted in Britain, Swami et al. (2011) found that, when entered into a multiple regression, political cynicism and attitude to authority predicted endorsement of the July 7, 2005 London bombing conspiracy (allegedly allowed or implemented by the British government rather than by Al Qaida). So did attitudes towards democracy but not satisfaction with life.

Imhoff and Bruder (2014) measure anomie in terms of the perception that society is becoming too complicated/confusing. They find that it is moderately associated with a general tendency to engage in conspiracy thinking (that they dub "conspiracy mentality").

In another indirectly relevant study, Wood, Sutton and Douglas (2012) found that belief in two contradictory conspiracy theories (the belief that Osama bin laden was already dead when the US raid to kill him was launched and the belief that he is still alive) was correlated and that this link was explained by the belief that officials are involved in a "cover up". Thus, a possible effect of anomie, distrust in authorities, seems to explain this paradoxical belief.

We also know that variables associated with anomie such as lack of control (Van Prooijen, 2009), social exclusion (Graeupner \& Coman, 2017) and uncertainty (Van Prooijen \& Jostmann, 2012) are associated with belief in conspiracy theories. This may be because these

\footnotetext{
1 The other factors are individualism, conservatism, fear of uncertainty and openness to experience.
} 
states lead people to make sense of their situation. Conspiracy theorizing is a response to this need (Van Prooijen, 2001).

Note that one aspect that is relatively ignored from this literature is the role of the collective aspect of meaning making. In this literature, meaning making is often viewed as an intraindividual process. Yet, there is good evidence that the collective elaboration of a consensual narrative within the group is necessary to validate this narrative (i.e., group consensus is a source of certainty: Hardin \& Higgins, 1996, Turner, 1991). Such a narrative also helps reestablish social ties within the minority group. Thus conspiracy theorizing may help restore the ties that have been severed by anomie. To the extent that conspiracy theories involve blaming a well defined outgroup, they may be particularly amenable to establishing such consensus and hence responding to anomie by a strengthening of social ties. For example, African Americans' perception that the delay in response to Hurrican Katrina was partly a function of racism can serve as a powerful device for enforcing within-group solidarity (i.e., "we can only count on ourselves", cf. Adams, O'Brian, \& Nelson, 2006).

Table 1 reports a summary of the variables associated with anomie that have been measured in the literature in order to predict conspiracy theories. As we can see, there are many such variables and they often have little conceptual overlap. In this regard, the scale developed by Teymoori et al. (2016) on a large international sample may prove helpful. These authors found that two dimensions subsumed the concept of anomie: the first refers to the breakdown of the social fabric, which includes items tapping social trust and moral decline. The second factor refers to breakdown of leadership. This includes attitudes towards the government as both legitimate, effective and caring about the welfare of the community. Some of the variables in table 1 (but not all) can be associated with one of these sub-dimensions. We can also witness that variables associated with each of the sub-dimensions predict endorsement of conspiracy theories.

Table 1: List of variables conceptually associated with anomie.

Dimensions of anomie proposed by

Teymoori et al. (2016)

\begin{tabular}{lccc}
\hline Variable & Source & $\begin{array}{c}\text { Breakdown } \\
\text { of Social }\end{array}$ & $\begin{array}{c}\text { Breakdown } \\
\text { of }\end{array}$ \\
\hline
\end{tabular}




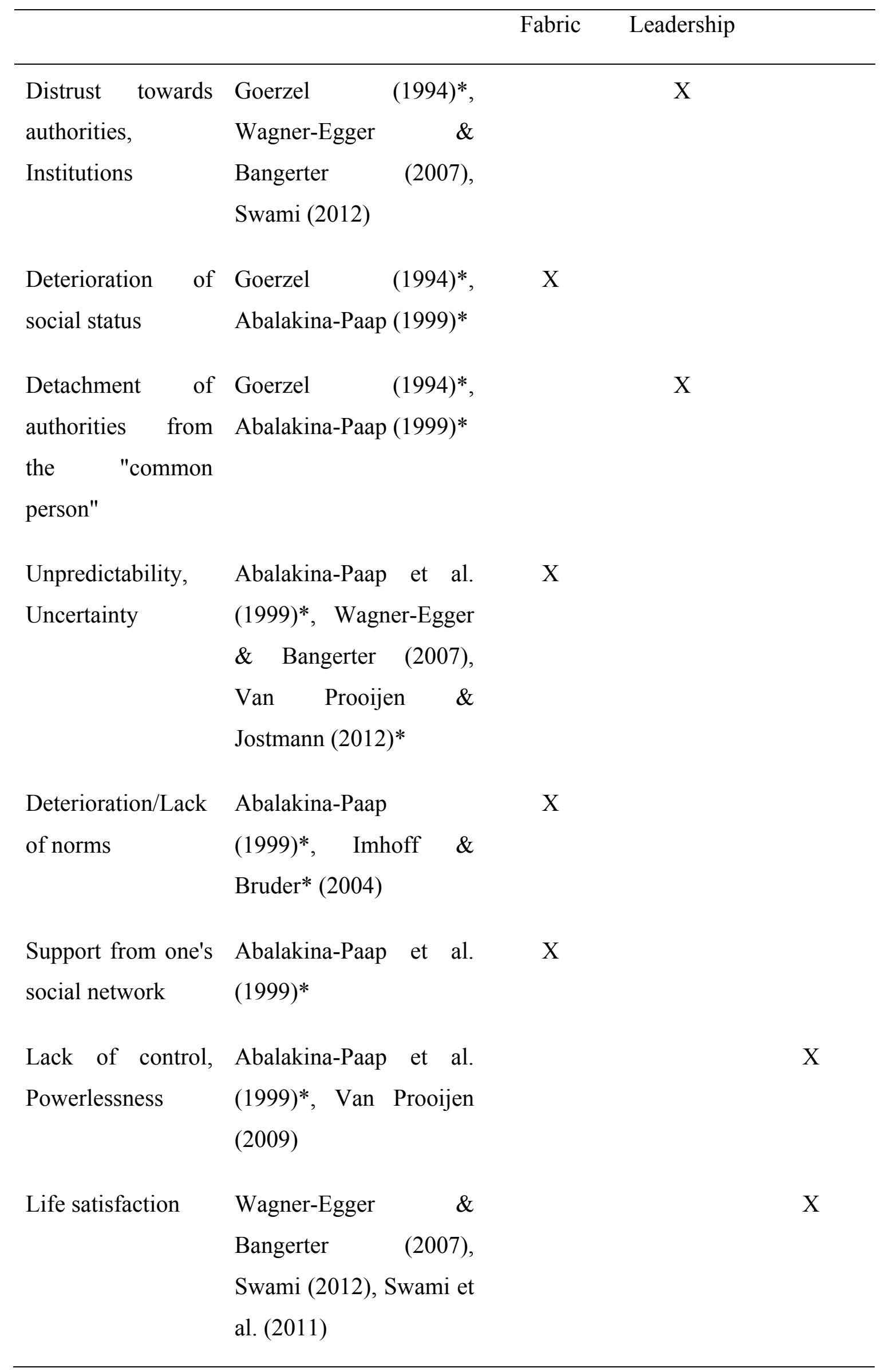


Political alienation Swami (2012)

(i.e., not

understanding

politics)

Attitudes towards Swami et al.*(2011) X

democratic

principles

$\begin{array}{lll}\text { Political Cynicism Swami et al.*(2011) X } & \text { X }\end{array}$

Note:

* Refers to a significant prediction of endorsement of conspiracy theories (or conspiracy mentality) in a multiple regression. With respect to the papers by Goerzel (1994) and Abalakina-Paap (1999), the subdimensions of anomie were not assessed separately (see text).

\section{Conclusion}

Based on this overview, we can make several observations:

- Given that anomie is a sociological concept, it is important to bear in mind that any explanation of the link between anomie and endorsement of CTs should be made at the group level. Thus, more "anomic" groups or societies should on average endorse CTs more than less "anomic" groups or societies. Showing for example that people who feel more uncertain within a society believe more in CTs than those who don't does not directly test this hypothesis. This approach is absent from the social psychological literature (to the best of my knowledge).

- Studies using a psychological version of anomie rely on vastly different measures that have often little conceptual overlap. This is due in part to the hybrid nature of the concept, which does not lend itself to straightforward operationalizations. The new scale developed by Teymoori et al. (2016) may prove very helpful in this respect. 
- The psychologization of anomie has led to a relative neglect of the collective dimension of conspiracy theories and how this collective aspect could play a key role in responding to the disruption of social ties inherent to anomie.

- Most of the studies bearing on anomie are cross-sectional, which renders statements about causality open to criticism. Longitudinal and experimental designs are called for.

\section{References}

Abalakina-Paap, M., Stephan, W. G., Craig, T., \& Gregory, W. L. (1999). Beliefs in conspiracies. Political Psychology, 20(3), 637-647.

Adams, G., O’Brien, L. T., \& Nelson, J. C. (2006). Perceptions of racism in Hurricane Katrina: A liberation psychology analysis. Analyses of social issues and public policy, 6(1), 215-235.

Durkheim, E. (1897). Le Suicide: Etude de Sociologie. Paris:Felix Alcan. Retreived from: http://www.gutenberg.org/files/40489/40489-8.txt

Goertzel, T. (1994). Belief in conspiracy theories. Political Psychology, 731-742.

Graeupner, D., \& Coman, A. (2017). The dark side of meaning-making: How social exclusion leads to superstitious thinking. Journal of Experimental Social Psychology, 69, 218-222.

Hardin, C. D., \& Higgins, E. T. (1996). Shared reality: How social verification makes the subjective objective. In R. M. Sorrentino \& E. T. Higgins (Eds.), Handbook of

Oliver, J. E., \& Wood, T. J. (2014). Conspiracy theories and the paranoid style (s) of mass opinion. American Journal of Political Science, 58(4), 952-966.

Srole, L. (1956). Social integration and certain corollaries: An exploratory study. American sociological review, 21(6), 709-716.

Swami, V. (2012). Social psychological origins of conspiracy theories: the case of the Jewish conspiracy theory in Malaysia. Frontiers in Psychology, 3, 280.

Teymoori, A., Jetten, J., Bastian, B., Ariyanto, A., Autin, F., Ayub, N., ... \& Cui, L. (2016).

Revisiting the measurement of anomie. PloS one, 11(7), e0158370.

Turner, J. C. (1991). Social influence. Thomson Brooks/Cole Publishing Co.

Van Prooijen, J. W., \& Acker, M. (2015). The influence of control on belief in conspiracy theories: Conceptual and applied extensions. Applied Cognitive Psychology, 29(5), 753-761. 
Van Prooijen, J. W., \& Jostmann, N. B. (2013). Belief in conspiracy theories: The influence of uncertainty and perceived morality. European Journal of Social Psychology, 43(1), 109115.

Volkan, V. (1988). The need to have enemies and allies. Northvale, NJ: Jason Aronson

Wagner-Egger, P., \& Bangerter, A. (2007). La vérite est ailleurs: corrélats de l'adhésion aux théories du complot. Revue internationale de psychologie sociale, 20(4), 31-61.

Wood, M. J., Douglas, K. M., \& Sutton, R. M. (2012). Dead and alive: Beliefs in contradictory conspiracy theories. Social Psychological and Personality Science, 3(6), 767-773. 